\title{
As políticas econômicas das ditaduras do Chile (1973-1982) e da Argentina (1976-1982) sob um ângulo comparativo
}

\author{
The economic policies of the dictatorships of Chile (1973-1982) and \\ Argentina (1976-1982) from a comparative angle
}

\author{
Marcos Taroco Resende**
}

\begin{abstract}
Resumo: O objetivo do artigo é analisar as políticas econômicas das ditaduras militares do Chile e da Argentina nas décadas de 1970 e 1980 e seus resultados. Para alcançar o objetivo, realiza-se uma análise documental de dados estatísticos da CEPAL, dos bancos centrais e outras fontes, e ainda de alguns discursos de ministros, além de uma revisão da literatura especializada. A principal contribuição do artigo é a abordagem comparativa. Os resultados indicam que apesar de algumas características em comum das políticas econômicas liberais de ambos os países, elas apresentam importantes diferenças entre si na aplicação e nos seus resultados econômicos. A principal diferença reside em um maior radicalismo no caso chileno, e maior pragmatismo na Argentina. Alguns dos aspectos que ajudam a explicar essa divergência são os condicionantes impostos pelos militares à aplicação da política econômica e a menor capacidade de blindagem do regime militar argentino em relação aos setores produtivos em comparação ao chileno.
\end{abstract}

Palavras-chave: Políticas Econômicas; Chile; Argentina; Liberalismo econômico; Regimes autoritários

Abstract: The objective of the article is to analyze the economic policies adopted during the military dictatorships of Chile and Argentina in the 1970s and 1980s and their results. To do so, we use data from various sources, such as ECLAC, central banks and speeches by ministers, besides a review of the scholarly literature. The main contribution of the article lies in its comparative approach. Even though the economic policies of both countries were liberal and shared some characteristics, there were also important differences in their application and economic results, which resided in a greater radicalism in the Chilean case and pragmatism in Argentina. One of the aspects that helps explain this difference are the constraints imposed by the military on the application of economic policy, and the lesser capacity for insulation against social demands exhibited by the Argentine military regime especially in relation to productive sectors, when compared to the Chilean.

\footnotetext{
*Submissão: 13/03/2020 | Aprovação: 16/05/2020 | DOI: 10.5380/re.v42i77.72257

** Bolsista CAPES e doutorando em Economia no CEDEPLAR/UFMG. Mestre em Economia pelo PPGEconomia/Unifal-MG. E-mail: marcostaroco07@ hotmail.com | ORCID: 0000-0003-2936-0096
}

Esta publicação está licenciada sob os termos de 
Keywords: Economic Policy; Chile; Argentina; Economic Liberalism; Authoritarian Regimes

JEL: N10; B10; E61 


\section{Introdução}

Um tema historicamente importante no debate público do século XX nos países da América Latina é a política econômica dos governos em distintos períodos e suas diferentes orientações ideológicas. É comum encontrar na literatura a periodização mais ou menos delimitada entre modelo de desenvolvimento industrializante liderado pelo Estado entre 1930 e meados de 1980, a partir do qual se iniciou um paradigma de retirada do Estado das diversas áreas da sociedade, e em especial da esfera produtiva (Bielschowsky, 2000; Cano, 2000).

Este quadro histórico geral nos proporciona uma importante ferramenta de inteligibilidade das tendências econômicas da América Latina como um todo. Entretanto, como é destacado pela literatura sobre a América Latina, há diferenças importantes nas trajetórias de desenvolvimento econômico dos países da região. Uma dessas diferenças a respeito da industrialização é a de que, a depender do país, houve respostas diferentes aos problemas estruturais comuns aos países latino-americanos. Neste sentido, enquanto Brasil e México avançaram mais no processo de industrialização, Argentina e Chile instauraram experiências neoliberais precocemente, antecipando em quase 20 anos a generalização dessas políticas para a economia mundial, e em particular para os países da América Latina (Ramos, 1984; Cano, 2000; Ffrench-Davis, Muñoz e Palma, 2009). Conforme a Tabela 1, em geral os desempenhos econômicos e de industrialização da Argentina e do Chile entre a década de 1950 e 1970 foram menores do que os de Brasil e México. 
Tabela 1 - Indicadores básicos de crescimento e desempenho industrial da América Latina, Brasil, México, Argentina e Chile.

\begin{tabular}{l|c|c|c|c|c|c}
\hline \multirow{2}{*}{ Região/País } & \multicolumn{2}{|c|}{ Crescimento do PIB (\%) } & $\begin{array}{c}\text { Crescimento do } \\
\text { produto } \\
\text { industrial }(\%)\end{array}$ & \multicolumn{2}{|c|}{$\begin{array}{c}\text { FBCF } \\
(\% \mathrm{PIB})\end{array}$} & \multicolumn{2}{|c}{$\begin{array}{c}\text { Participação da } \\
\text { indústria no PIB } \\
(\%)\end{array}$} \\
\cline { 2 - 8 } & $1950-1960$ & $1960-1970$ & $1950-1970$ & $1950-1970$ & 1950 & 1970 \\
\hline América Latina & 5,5 & 5,8 & 7 & 17,2 & 19,9 & 25,7 \\
Brasil & 6,8 & 6,1 & 8,1 & 17,5 & 21,9 & 29,3 \\
México & 6,1 & 7 & 8,2 & 16,7 & 17,2 & 22,9 \\
Argentina & 3 & 4,3 & 5,1 & 16,6 & 23,8 & 30,1 \\
Chile & 3,6 & 4,2 & 4 & 14,6 & 25,6 & 25,5 \\
\hline
\end{tabular}

Fonte: Elaborada pelo autor com base nos dados da CEPAL (2009).

Notas: Valores a partir de dados em milhões de dólares constantes de 1970.

É nas trajetórias nacionais em perspectiva comparada que nos concentraremos nesse artigo, comparando as políticas econômicas das ditaduras militares de Chile (1973-1982) e Argentina (1976-1982). Ou seja, tratamos de comparar casos de aplicações de políticas econômicas inspiradas no liberalismo econômico, visando ressaltar que a adoção de um conjunto de ideias econômicas similares produz aplicações e resultados diferentes, a depender dos contextos específicos. O recorte temporal da pesquisa repousará no período cujo início é o golpe de cada regime, setembro de 1973 no caso do Chile e março de 1976 no caso da Argentina, estendendo-se até 1982 para os dois casos. Esse recorte até 1982 se justifica porque este ano é um marco para a crise da dívida externa nesses países, que levou a queda dos principais membros das respectivas equipes econômicas: Sérgio de Castro Spikula, que esteve no comando do Ministério da Fazenda chileno desde o fim 1976 até abril de 1982, e José Alfredo Martínez de Hoz no Ministério da Economia argentino desde o início do regime até março de 1981.

Como os objetivos da pesquisa se remetem aos casos nacionais, Argentina e Chile, para além desta introdução e da conclusão, o artigo é composto por mais três seções. Nas seções 2 e 3, estudam-se as políticas econômicas liberais de Chile e Argentina, respectivamente, apontando em geral os resultados das políticas econômicas em cada caso, comparando-os. Na seção 4, discutimos algumas possíveis diferenças encontradas, isto é, na formulação da política econômica. Para tanto, privilegiamos os condicionantes militares para a política econômica e a blindagem social do regime em relação a determinados setores produtivos, como o setor industrial. 
Por condicionantes dos militares à política econômica entendemos tanto as restrições e vetos de quais medidas podiam ser implementadas como a relação entre os militares e os ministros responsáveis pela direção da economia. O significado de blindagem social adotado neste trabalho é simplesmente a maneira como os ministros se relacionavam com os setores produtivos, no sentido de que certas políticas podiam ser aplicadas, apesar dos efeitos contrários a determinados interesses.

\section{As políticas econômicas da ditadura Chilena (1973-1982): o radicalismo monetarista}

Após o violento golpe militar que retirou do poder o Presidente Salvador Allende, da Unidade Popular (UP), o Chile entrou em um período de profundas transformações na economia e na sociedade, com um regime repressivo que atravessou os anos 1980, findando no ano de 1990. O golpe militar de 1973 que levou a Junta Militar, sob a liderança do General Augusto Pinochet, ao poder no Chile configurou-se no campo econômico pela decisão de buscar restaurar os "equilíbrios macroeconômicos básicos" da economia chilena e deixar para trás o processo de substituição de importações. No campo político as motivações da ditadura eram liquidar a "desordem pública" e a crise social derivadas da ascensão da Unidade Popular, que impulsionavam desde 1970 um processo de orientação socialista no país, com várias nacionalizações de bancos, empresas e radicalização da reforma agrária (Angel, 2002).

A tecnocracia à frente das questões econômicas do regime foi composta por um grupo de jovens economistas conhecidos como "Chicago boys". Esses economistas fizeram pós-graduação em economia na Universidade de Chicago, nos Estados Unidos, através de um convênio firmado entre a referida universidade e a Pontifícia Universidade Católica do Chile (PUC) em 1955, tendo como docentes várias personalidades monetaristas da época, tais como Milton Friedman e Arnold Harberger (Fuentes e Valdeavellano, 2015; Valdés, 1995). Os Chicago boys organizaram várias reuniões entre 1969 e 1973 para discussão de políticas econômicas que culminaram na elaboração do Programa de Desarrollo 
Económico, conhecido como "El Ladrillo", que serviu de base para as políticas econômicas implementadas no regime Pinochet (Castro, 1992).

Visando explorar os aspectos da implementação e os resultados da política econômica dos Chicago boys, nesta seção discutiremos a aplicação das políticas econômicas no Chile durante o período de 1973 a 1982. Para tanto, nos baseamos na periodização em três fases adotada por Ramos (1984). A primeira fase se estende do golpe (setembro de 1973) a junho de 1976, sendo caracterizada pelos problemas mais imediatos como a reorganização do sistema de preços, os mercados negros e a inflação. A segunda fase se inicia em junho de 1976 até meados de 1981, sendo caracterizada pelo aprofundamento da tentativa de controle inflacionário via câmbio e a realização de reformas estruturais. Por último, a terceira fase, compreendida entre meados de 1981 até 1983, foi marcada por sérios problemas no balanço de pagamentos. Analisaremos cada uma dessas fases em subseções, realizando as comparações pertinentes.

\subsection{Primeira fase: os problemas conjunturais após o golpe}

$\mathrm{Na}$ primeira fase, a política econômica do regime militar priorizou a estabilização macroeconômica em seus problemas mais imediatos, pautando suas medidas primeiramente no problema da hiperinflação - que alcançou $700 \%$ quando anualizada à taxa média mensal nos últimos quatro meses da Unidade Popular (Ffrench-Davis, 2003) — e da existência de mercados negros em função da escassez gerada pelo controle de preços do governo deposto (Angell, 2000; Ffrench-Davis, 2003; Ramos, 1984). A escassez dos mercados foi resolvida pelo fim dos controles sobre os preços (Ffrench-Davis, 2003).

\footnotetext{
${ }^{1}$ Em uma tradução livre, seria "O tijolo" (em português). Sérgio de Castro explica que o documento de política econômica apresentado à Junta Militar de Pinochet - pelo contato que Emílio Sanfuentes tinha com a Marinha - ficou assim conhecido devido a suas dimensões similares a de um tijolo. A história desse plano remonta 1969 quando uma versão preliminar foi apresentada a Jorge Alessandri, candidato da direita derrotado por Salvador Allende nas eleições presidenciais de 1970, que achou o plano muito radical e não o incorporou a sua campanha (Fuentes e Valdeavallano, 2015).
} 
Tabela 2 - Indicadores fiscais, taxa de investimento e inflação no Chile (1973-1982)

\begin{tabular}{|c|c|c|c|c|c|c|c|c|c|c|}
\hline \multirow{2}{*}{ Indicadores } & \multicolumn{10}{|c|}{ Ano } \\
\hline & 1973 & 1974 & 1975 & 1976 & 1977 & 1978 & 1979 & 1980 & 1981 & 1982 \\
\hline Arrecadação corrente (1) & ... & 30,3 & 34,9 & 37,4 & 38,6 & 33,2 & 32,5 & 32,9 & 32,1 & 29,9 \\
\hline Gasto público corrente (2) & $\ldots$ & 26,4 & 27,6 & 31,0 & 33,0 & 26,8 & 24,8 & 24,5 & 26,7 & 31,9 \\
\hline Resultado corrente $3=(1-2)$ & $\ldots$ & 3,9 & 7,3 & 6,4 & 5,6 & 6,5 & 7,7 & 8,4 & 5,5 & $-1,9$ \\
\hline Investimento público (4) & $\ldots$ & 8,7 & 5,7 & 3,1 & 4,2 & 3,5 & 3,2 & 2,6 & 2,5 & 2,1 \\
\hline Resultado fiscal $=5=(3-4)$ & $\ldots$ & $-6,6$ & 0,0 & 3,2 & 0,9 & 2,1 & 5,1 & 5,5 & 2.9 & $-2,3$ \\
\hline Resultado das empresas estatais (6) & $\ldots$ & 1,2 & $-2,1$ & 0,9 & $-0,5$ & $-0,8$ & 0,6 & $-0,1$ & $-2,5$ & $-1,6$ \\
\hline Investimentos das empresas estatais (7) & $\ldots$ & 3,9 & 3,5 & 3,0 & 2,7 & 3,2 & 1,9 & 2,6 & 2,6 & 2,6 \\
\hline Resultado do SPNF $8=(5+6)$ & $\ldots$ & $-5,5$ & $-2,1$ & 4,0 & 0,4 & 1,3 & 4,6 & 5,4 & 0,4 & $-3,9$ \\
\hline Investimento público total $(4+7)$ & $\ldots$ & 12,6 & 9,2 & 6,1 & 6,9 & 6,7 & 5,1 & 5,2 & 5,1 & 4,7 \\
\hline Formação Bruta de capital fixo & 15,3 & 18,1 & 16,0 & 13,2 & 13,9 & 15,0 & 16,2 & 18,3 & 20,1 & 14,4 \\
\hline Inflação - IPC corrigido & 453,7 & 513,1 & 377,8 & 210,7 & 91,7 & 40,2 & 33,4 & 35,1 & 19,7 & 9,9 \\
\hline
\end{tabular}

Fonte: Informações fiscais: Marshall e Schmidt-Hebbel (1994). Taxa de investimento: CEPAL (2009). Inflação: Córtazar e Marshall (1980) e Yañez (1984).

Notas: Dados fiscais e taxa de investimento em proporção do PIB; SPNF - Setor Público não financeiro. O Resultado setor público não financeiro está em termos nominais, sendo igual o resultado fiscal mais os juros da dívida pública; Formação Bruta de Capital Fixo (\%PIB) é a taxa de investimento da economia.

O resultado imediato da opção da política econômica foi que os níveis de preços se elevaram muito acima das expectativas inflacionárias reprimidas. Este efeito era esperado, pois se tratava do fenômeno conhecido pelos economistas como "inflação corretiva", que é aquela inflação necessária para reestabelecer o nível de preços relativos da economia. Ramos (1977) estima que a liberação dos preços ocasionou um salto excessivo muito acima do "equilíbrio". A política antiinflacionária do governo, conjugando liberalização de preços e políticas monetária e fiscal restritivas, corroeu os salários reais e a atividade econômica (Angell, 2002; Ffrench-Davis, 2003). O esforço do governo chileno em reduzir a inversão pública ajuda a explicar a baixa taxa de investimento do Chile no período, que se reduziu de 15,3\% em 1973 para 13,2\% em 1976. Os dados da Tabela 3 mostram uma deterioração das remunerações reais em 1975 e consequentemente redução do PIB e do PIB per capita, o que induziu aumentos progressivos na taxa de desemprego.

Essa questão é uma das principais marcas do radicalismo da política econômica chilena em relação à experiência Argentina. No Chile, a recessão da atividade econômica e o aumento do desemprego, em função do tratamento radical preconizado pelos Chicago boys, foram tolerados por Pinochet. Esta maneira de combate à inflação pelos cortes drásticos do gasto público e do investimento público é uma característica importante da política econômica do regime chileno. 


\section{Tabela 3 - Indicadores de crescimento, desemprego e remunerações no Chile (1973-1982)}

\begin{tabular}{c|c|c|c|c|c|c|c|c}
\hline \multirow{2}{*}{ Ano } & \multicolumn{8}{|c}{ Indicador macroeconômico } \\
\cline { 2 - 10 } & $\begin{array}{c}\text { Produto } \\
\text { Interno } \\
\text { Bruto }\end{array}$ & $\begin{array}{c}\text { Taxa de } \\
\text { variação } \\
\text { do PIB }\end{array}$ & $\begin{array}{c}\text { PIB per } \\
\text { capita }\end{array}$ & $\begin{array}{c}\text { Taxa de } \\
\text { variação do } \\
\text { PIB per } \\
\text { capita }\end{array}$ & $\begin{array}{c}\text { Taxa de } \\
\text { desemprego } \\
\text { aberta }\end{array}$ & $\begin{array}{c}\text { Taxa de } \\
\text { desemprego } \\
\text { com PEM }\end{array}$ & $\begin{array}{c}\text { Taxa de } \\
\text { desemprego } \\
\text { com PEM E } \\
\text { POJ }\end{array}$ & $\begin{array}{c}\text { Índice de } \\
\text { salários } \\
\text { reais }\end{array}$ \\
\hline 1973 & 19728,6 & $-5,6$ & 1956,0 & $-7,1$ & 4,8 & $\ldots$ & $\ldots$ & 73 \\
1974 & 19920,9 & 1,0 & 1943,3 & $-0,7$ & 9,1 & $\ldots$ & $\ldots$ & 68 \\
1975 & 17349,1 & $-12,9$ & 1666,1 & $-14,3$ & 15,7 & 17,6 & $\ldots$ & 61 \\
1976 & 17959,4 & 3,5 & 1699,4 & 2,0 & 16,7 & 21,9 & $\ldots$ & 62 \\
1977 & 19730,0 & 9,9 & 1841,2 & 8,3 & 13,3 & 18,9 & $\ldots$ & 71 \\
1978 & 21351,1 & 8,2 & 1965,7 & 6,8 & 13,8 & 18 & $\ldots$ & 74 \\
1979 & 23119,4 & 8,3 & 2099,3 & 6,8 & 13,5 & 17,3 & $\ldots$ & 74 \\
1980 & 24956,3 & 7,9 & 2233,4 & 6,4 & 11,7 & 17 & $\ldots$ & 83 \\
1981 & 26506,6 & 6,2 & 2336,0 & 4,6 & 10,4 & 15,1 & $\ldots$ & 96 \\
1982 & 22905,0 & $-13,6$ & 1987,2 & $-14,9$ & 19,6 & 25,6 & 26,1 & 94 \\
\hline
\end{tabular}

Fonte: PIB (milhões de US\$ de 1980), PIB per capita, taxas de crescimento: CEPAL (2009). Taxas de desemprego: Jadresic (1986, p. 151). Índice de salários reais: Jadresic (1990, p. 14).

Notas: Taxas de variação Taxas de variação do PIB e do PIB per capita de um ano com relação ao ano anterior; Índice de salários reais com ano base em $(1970=100)$.

Embora a política anti-inflacionária de "tratamento de choque" iniciada em 1975 tenha levado à queda acentuada da atividade econômica, redução do déficit público, controle monetário e deterioração dos salários, a inflação não tinha obtido uma redução ainda tão satisfatória, estando resistente a níveis superiores a 300\% nos três primeiros anos de duração de tentativa de estabilização no Chile. O fato de a economia chilena durante a primeira fase ter apresentado certa resistência à baixa da inflação, mesmo com a recessão, colocava em xeque as explicações teóricas dos Chicago boys (Angell, 2002; Ffrench-Davis, 2003; Ramos, 1977, 1984). Isto porque, segundo a teoria monetarista, os cortes dos gastos públicos implicariam em redução da demanda, e por consequência diminuição da inflação. A forte recessão de 1975, de redução de $13 \%$ no PIB, e a persistência da inflação em níveis elevados implicavam que existiam outros aspectos relevantes para explicar a dinâmica inflacionária, como a existência da inércia inflacionária, uma situação na qual os agentes econômicos promovem reajustes de preços, através, por exemplo, de contratos e aluguéis, com base na inflação passada. 


\subsection{Segunda fase: a política anti-inflacionária e as reformas estruturais}

Em meados de 1976 foi iniciada a segunda fase da política econômica da ditadura. Neste período, logrou-se uma efetividade maior na política antiinflacionária, com a mudança no diagnóstico da inflação e sua estratégia de combate, e a economia chilena obteve os melhores indicadores macroeconômicos sob o regime de exceção (Ramos, 1984). A equipe econômica reconheceu que a política monetária restritiva não era suficiente para dar fim ao processo inflacionário. Desta forma, houve um reconhecimento de que a inflação não derivava apenas do excesso de demanda, mas havia em jogo outras causas como as expectativas dos agentes econômicos e a indexação (Angell, 2002; Ramos, 1977).

Neste sentido, a principal variável escolhida para efetuar o controle inflacionário foi a taxa de câmbio. No início da experiência monetarista, o peso chileno foi desvalorizado para contornar o déficit em conta corrente e manter o poder de compra real da moeda. No entanto, na nova estratégia contra a inflação, através do enfoque monetário do balanço de pagamentos, a desvalorização cambial passou a ser a taxas inferiores à inflação passada, para efetuar a valorização do câmbio real (Tabela 4). Essa estratégia era apoiada na concorrência externa pela abertura comercial (redução das tarifas) a fim de estimular as importações para baixar os preços e reordenar as expectativas inflacionárias dos agentes econômicos. Como resultado dessa nova estratégia utilizando o câmbio, houve uma redução sistemática da taxa de inflação (Tabela 2). 
Tabela 4 - Indicadores do setor externo do Chile (1973-1982)

\begin{tabular}{|c|c|c|c|c|c|c|c|c|c|c|}
\hline \multirow{2}{*}{ Indicador } & \multicolumn{10}{|c|}{ Ano } \\
\hline & 1973 & 1974 & 1975 & 1976 & 1977 & 1978 & 1979 & 1980 & 1981 & 1982 \\
\hline $\begin{array}{l}\text { Taxa de câmbio } \\
\text { nominal }\end{array}$ & 110,70 & 831,90 & 4,91 & 13,05 & 21,40 & 31,66 & 37,25 & 39,00 & 39,0 & 50,91 \\
\hline $\begin{array}{l}\text { Desvalorização } \\
\text { nominal anual } \\
\text { da moeda }\end{array}$ & 468,6 & 651,4 & $\cdots$ & 165,8 & 64,9 & 47,0 & 17,6 & 4,7 & 0 & 30,5 \\
\hline $\begin{array}{l}\text { Índice da taxa de } \\
\text { câmbio real } \\
\text { efetiva }\end{array}$ & 107,2 & 93,5 & 100,2 & 87,1 & 84,4 & 97,7 & 87,4 & 75,1 & 67,4 & 78,9 \\
\hline $\begin{array}{l}\text { Tarifa máxima } \\
\text { de importações }\end{array}$ & 220,0 & 200,0 & 120,0 & 80,0 & 55,0 & 20,0 & 10,0 & $\cdots$ & $\ldots$ & ... \\
\hline $\begin{array}{l}\text { Tarifa média } \\
\text { simples }\end{array}$ & 94,0 & 90,0 & 52,0 & 38,0 & 24,0 & 13,9 & 10,1 & $\cdots$ & $\cdots$ & $\ldots$ \\
\hline $\begin{array}{l}\text { Balança } \\
\text { Comercial }\end{array}$ & $-184,0$ & $-36,0$ & $-211,0$ & 433,0 & $-267,0$ & $-680,0$ & 598,0 & $-1056,0$ & -3245 & $-379,0$ \\
\hline Exportações & 1463,0 & 2327,0 & 1838,0 & 2413,0 & 2604,0 & 2941,0 & 4619,0 & 5968,0 & 5008,0 & 4641,0 \\
\hline Importações & 1646,0 & 2363,0 & 2049,0 & 1980,0 & 2871,0 & 3621,0 & 5217,0 & 7023,0 & 8253,0 & 5020,0 \\
\hline $\begin{array}{l}\text { Balança em } \\
\text { conta corrente }\end{array}$ & $-288,0$ & $-301,0$ & $-498,0$ & 132,0 & -567 & $-1111,0$ & $-1205,0$ & $-2020,0$ & -4805 & $-2373,0$ \\
\hline Conta capital & 387,0 & 210,0 & 212,0 & 199,0 & 738,0 & 1854,0 & 2261,0 & 3341,0 & 4941,0 & 1032,0 \\
\hline $\begin{array}{l}\text { Saldo balanço } \\
\text { de pagamentos }\end{array}$ & 99,0 & $-90,0$ & $-285,0$ & 330,0 & 170,0 & 744,0 & 1056,0 & 1321,0 & 136,0 & $-1340,0$ \\
\hline $\begin{array}{l}\text { Variação das } \\
\text { reservas }\end{array}$ & $-15,0$ & 176,0 & 184,0 & $-272,0$ & $-125,0$ & $-683,0$ & -1061 & $-1331,0$ & $-164,0$ & 1112 \\
\hline
\end{tabular}

Fonte: Taxa de câmbio real: Ramos (1984); Taxa de câmbio nominal: Banco Central de Chile (2001); Desvalorização nominal anual: Anuário Estatístico da CEPAL. tarifas máxima e média: Ffrench-Davis (2003, p. 119). Desvalorização nominal anual: Ramos (1984). Contas do balanço de pagamentos: CEPAL (2009).

Notas: Taxa de câmbio de acordo com moeda legal do período (escudo até 1974 e peso após 1975). Por isso há uma forte mudança na taxa de câmbio nominal na tabela entre esses dois anos.

Tarifas em porcentagem; Valores negativos da variação de reservas internacionais significam aumentos; Índice da taxa de câmbio real efetiva com base em 1970 (=100); Contas externas em milhões de US\$ correntes.

Outro aspecto caracterizador da segunda fase foi o forte crescimento econômico. A redução da inflação aliada à forte entrada de capitais externos atraídos pelas taxas de juros reais altas contribuíram para o aumento dos salários reais e da produção (Ffrench-Davis, 2003; Ramos, 1984). A taxa média de crescimento anual da economia chilena medida pelo PIB foi de 7,6\% entre 1976 e 1980 (Tabela 3), o que contrasta fortemente com a taxa média de crescimento de - 
1,3\% entre 1970 e 1975 (CEPAL, 1980). Ao mesmo tempo, os dados da Tabela 3 sinalizam aumento na taxa de investimento e recuos nas taxas de desemprego, apesar de ainda elevadas. Esses resultados construíram uma imagem de propaganda do "milagre econômico" chileno (Ffrench-Davis, 2003; Valdés, 1995). Vale destacar, entretanto, que essa noção de um milagre econômico foi construída com base apenas no período 1976-1982 - quando se considera o período total de 1973 a 1982, o PIB havia crescido em média apenas 1,3\% e o PIB per capita $0,2 \%$, estacionando o nível de renda per capita do Chile neste ano, a um nível apenas levemente superior a 1973 (Tabela 3).

Um aspecto importante que ronda a segunda fase, mas que atravessa as três, é a efetivação das reformas estruturais implementadas pelos Chicago boys, que no caso argentino encontrou mais dificuldades, tais como o plano laboral, a reforma da previdência, a reforma financeira, a reforma administrativa, a abertura comercial e a maior inserção da agricultura nos mercados globais (Castro, 1981).

Dentre essa gama de reformas estruturais destacamos algumas que representam sua radicalidade. Conforme argumenta Arenas de Mesa (2010), a reforma do sistema de pensões no Chile em 1980, que instituiu o regime de capitalização em substituição ao sistema de repartição, é considerada pioneira na América Latina e foi tomada como modelo nas políticas do Banco Mundial, e desde então 11 países fizeram reformas similares. A reforma previdenciária é um dos símbolos da capacidade de realização de reformas radicais dos Chicago boys.

Além da reforma da previdência, pelos dados da Tabela 4, podemos observar a radicalidade da abertura comercial, pelo rápido declínio das tarifas máximas e médias para $10 \%$. Outro exemplo é a redução do tamanho do Estado mediante processo de privatização. Além das empresas que sofreram intervenção do governo da Unidade Popular, o Estado chileno possuía através da Corporación de Fomento de la Producción (CORFO), 300 empresas estatais em 1973. Este número foi reduzido para 24 em 1980, das quais a metade estava em processo de privatização. Os militares chilenos resistiram em vender empresas que consideravam estratégicas para a segurança nacional, como a CODELCO e a ENAP (respectivamente, as empresas estatais de cobre e petróleo) (Angell, 2002). 


\subsection{A terceira fase: a explosão dos desequilíbrios no setor externo chileno}

Como contrapartida ao crescimento mais forte entre 1976 e 1980, a estratégia de valorização cambial potencializou os aspectos negativos da deterioração da situação externa do Chile na década de 1970 (Tabela 4). Desta forma, a política econômica se tornava cada vez mais dependente da entrada de capitais estrangeiros e do endividamento, e a explosão dos desequilíbrios era questão de tempo. A dívida externa total do Chile cresceu cerca de 3,5 vezes nesses quatro anos (Banco Central de Chile, 2001; Ramos, 1984).

Na terceira fase (meados de 1981 até 1983) a fragilidade da estratégia econômica do governo foi exposta. A redução das tarifas externas e a valorização da moeda barateavam as importações e desestimulavam as exportações, com a consequente deterioração da balança comercial e da conta corrente, à medida que essa dinâmica ficava altamente dependente do fluxo de capitais estrangeiros.

No ano de 1981 as contas do setor externo se desequilibraram de maneira notável. O déficit comercial mais que triplicou, enquanto e saldo negativo da conta corrente mais que dobrou. Ao mesmo tempo, a conta capital cresceu apenas 47\% (Tabela 4). Para aliviar a restrição externa, o governo teve que abandonar o câmbio fixo (a 39 pesos por dólar), desvalorizando o câmbio em 30\% nominalmente e aproximadamente $11 \%$ em termos reais, medidas que ajudaram a resolver de modo relativo os problemas externos nos anos subsequentes (Angell, 2002).

O endividamento da economia, e do setor privado, as altas taxas de juros, conforme a Tabela 4, e a recessão na atividade produtiva levaram a um aumento na inadimplência interna do mercado financeiro, principalmente dos bancos e empresas privadas. Para salvar os bancos e tais empresas do setor agrícola, industrial e de construção e evitar um colapso do sistema financeiro foi fundamental a intervenção estatal. Em 1981 o governo interviu em 8 instituições financeiras (Ramos, 1984).

\section{A política econômica do regime militar Argentino (1976-1983): ecletismo e pragmatismo}

Após o golpe de 24 de março de 1976, a institucionalização do regime autoritário argentino se deu por meio da ascensão de uma Junta Militar, formada pelo General Jorge Rafael Videla (Exército), Almirante Emílio Eduardo Massera (Marinha) e Brigadeiro Orlando Ramón Agosti (Força Aérea). Com Rafael Videla 
tornando-se o Presidente, deu-se início ao "Processo de Reorganização Nacional". As intenções do regime instituído eram eliminar as ameaças subversivas identificadas no peronismo e nas guerrilhas - dar fim à corrupção e superar a crise econômica (Canitrot, 1980; Ferrer, 2004; Torre e Riz, 2002).

Do ponto de vista político e social, pode-se afirmar que os motivos da tomada de poder relacionam-se com a incapacidade do sistema político argentino em resolver os conflitos sociais dentro das regras do jogo do sistema democrático (Canitrot, 1980; Fausto e Devoto, 2004; Ferrer, 2004). Do ponto de vista econômico, é consenso na literatura que um dos motivos que levaram à mudança nas políticas econômicas pelo regime autoritário, inclinando-se para o monetarismo, foi a frustração do crescimento econômico a partir da estratégia da Industrialização por Substituição de Importações (ISI), iniciada nas décadas de 30 e 40 e fortalecida no pós-guerra (Canitrot, 1980; Ferrer, 2004; 2012; Ramos, 1984; Rapoport, 2000). Para a resolução dos problemas econômicos, o regime optou, no plano de intenções, pelo liberalismo econômico, convidando para Ministro da Economia, Martínez de Hoz, que tinha prestígio frente ao empresariado argentino e os mercados financeiros internacionais.

Assim como no caso chileno, Ramos (1984) divide a gestão da política macroeconômica do regime militar argentino em três fases. A primeira entre abril de 1976 e maio de 1978, a segunda entre maio de 1978 e inícios de 1981, e a terceira a partir de 1981 até 1983 . Assim, como realizado no caso chileno, a cada fase corresponderá a uma subseção, em que se apresentam os principais indicadores econômicos.

\subsection{A primeira fase: $o$ setor externo e o combate à inflação}

Assim que assumiu o Ministério da Economia, o setor externo foi escolhido por Martínez de Hoz como uma das áreas mais críticas da situação econômica do país. As reservas internacionais dos países estavam praticamente esgotadas, mas conseguiu, pelo prestígio do ministro com os mercados financeiros internacionais, um empréstimo stand-by com o FMI no valor de US\$ 300 milhões e mais 100 milhões com um conjunto de bancos privados liderados pelo Chase Manhattan, impedindo a insolvência externa (Torre e Riz, 2002, p. 129). Para contornar o problema do balanço de pagamentos, deu-se fim às múltiplas taxas de câmbio e promoveu-se desvalorizações cambiais. 
Inicialmente, a política anti-inflacionária do governo, de inspiração ortodoxa, combinou congelamento dos salários nominais por três meses e um forte ataque contra a organização dos trabalhadores através da intervenção direta nos sindicatos, suspensão das atividades sindicais e direito de greve, reforma da Ley de Contratos de Trabajo etc. (Ferrer, 2004; Rapoport, 2000; Torre e Riz, 2002). Dado que ao mesmo tempo em que os salários nominais se encontravam congelados, deu-se início à liberalização de preços, resultando em uma diminuição abrupta dos salários reais. Os dados da Tabela 5 mostram que os salários reais terminaram 1976 com uma deterioração aproximada de $25 \%$ em relação a 1970 (base do índice).

Tabela 5 - Indicadores fiscais, inflação, desemprego e remunerações na Argentina (1976- 1982)

\begin{tabular}{l|c|c|c|c|c|cc}
\hline \multirow{1}{*}{\multicolumn{1}{c}{ Indicador }} & \multicolumn{7}{c}{ Ano } \\
\cline { 2 - 8 } & $\mathbf{1 9 7 6}$ & $\mathbf{1 9 7 7}$ & $\mathbf{1 9 7 8}$ & $\mathbf{1 9 7 9}$ & $\mathbf{1 9 8 0}$ & $\mathbf{1 9 8 1}$ & $\mathbf{1 9 8 2}$ \\
\hline Arrecadação total & 27,8 & 28,9 & 31,3 & 31,8 & 33,8 & 33,0 & 30,5 \\
Gasto público total & 39,5 & 33,6 & 37,8 & 38,4 & 41,2 & 46,2 & 45,6 \\
Investimento público & 13,1 & 13,3 & 12,5 & 10,5 & 9,5 & 9,7 & 8,6 \\
Resultado primário & $-10,2$ & $-3,6$ & $-4,6$ & $-4,5$ & $-5,6$ & $-9,4$ & $-8,8$ \\
Resultado do setor público & $-11,7$ & $-4,4$ & $-6,5$ & $-6,5$ & $-7,5$ & $-13,3$ & $-15,1$ \\
não financeiro (\%PIB) & $-13,9$ & $-4,3$ & $-8,8$ & $-9,3$ & $-6,6$ & $-13,5$ & $-40,6$ \\
Resultado fiscal total & 444,1 & 176 & 175,5 & 159,5 & 100,8 & 104,5 & 164,8 \\
Inflação - IPC & 4,6 & 3,0 & 2,9 & 2,1 & 2,2 & 4,5 & 4,7 \\
Taxa de desemprego & 74,7 & 73,6 & 72,3 & 83,0 & 92,8 & 83,0 & 74,1 \\
Índice de salários reais & 24,8 & 28,2 & 25,4 & 25,3 & 26,3 & 23,7 & 19,6 \\
\hline Formação Bruta de capital fixo & & & & & &
\end{tabular}

Fonte: Informações fiscais: Rodríguez (1994) a partir de dados do Ministério da Economia da Argentina. Inflação: Banco Central de la República Argentina, 1976-1983. Formação Bruta de Capital Fixo: CEPAL (2009). Taxa de desemprego: Ramos (1984).

Notas: Dados fiscais e taxa de investimento como proporção do PIB; Taxa de desemprego como proporção da força de trabalho; Índice de salários reais com ano base em $1970(1970=100)$.

Em meados de 1976 a inflação parecia ser um problema resolvido por causa do congelamento dos salários e redução do consumo, porém assim que a variável salários foi novamente liberada houve um incremento significativo da inflação (ainda que não tenha voltado ao nível inicial). Esse aumento da inflação elevou em muito as expectativas inflacionárias, o que fez com que a equipe econômica implementasse um congelamento de preços por 120 dias (entre março e junho de 
1977), que não foi efetivo no controle inflacionário (Rapoport, 2000; Torre e Riz, 2002). A inflação não cedia mesmo com avanços nos aspectos fiscais do governo, com aumento da arrecadação e certa diminuição dos gastos públicos (Tabela 5).

A literatura em geral ressalta que, no caso da Argentina, há uma singularidade, qual seja, havia pragmatismo e hesitação na redução da inversão pública. Por exemplo, Fausto e Devoto (2004) indicam isso como uma evidência do temor que as consequências em termos de bem-estar abrissem brecha para críticas ao regime. Percebe-se pelos dados da Tabela 6, que o investimento público (\%PIB) permaneceu em média a 13\% durante entre 1976 e 1978, a partir de quando houve certa redução para níveis próximos de 9,5\% entre 1979 e 1982. Isso contribuiu para baixas taxas de desemprego, menores que 5\% em todos os anos (Tabela 5).

O combate à inflação é um exemplo notável da maneira como se manifestava o ecletismo de Martínez de Hoz na condução da política econômica. Dadas as restrições de não elevação da recessão e do desemprego, o ministro alterou diagnósticos e medidas, passando desde o combate à inflação pelo meio tradicional da redução do déficit público, o congelamento de preços e conforme iremos enfatizar agora pela valorização real da taxa de câmbio, tentando atacar o problema da inércia inflacionária.

\subsection{Segunda fase: a tablita e as reformas estruturais}

Dado que os resultados em matéria fiscal não se manifestavam no descenso maior da inflação, na segunda fase (1978-1981) houve uma mudança do enfoque estabilizador para um enfoque na balança de pagamentos (monetarismo de economia aberta), que levou a uma crescente valorização real da taxa de câmbio, que por outro lado aumentou a vulnerabilidade da economia, abrindo caminho para a crise (Canitrot, 1980; Ramos, 1984).

A política cambial implementada a partir de dezembro de 1978 na administração do câmbio ficou conhecida como tablita. Conforme assinalado na Tabela 6, após uma desvalorização inicial de 5,23\%, houve progressivamente desvalorizações programadas decrescentes - as taxas de desvalorização cambial foram menores que a taxa de inflação interna - até alcançar um câmbio fixo em 1981. Conforme a Tabela 5, em 1979, com a implementação da política conhecida 
como tablita, a inflação baixou levemente para $160 \%$ e em 1980, houve um descenso maior para $100 \%$.

Tabela 6 - Indicadores do setor externo da Argentina - 1976-1983.

\begin{tabular}{|c|c|c|c|c|c|c|c|}
\hline \multirow{2}{*}{ Indicador } & \multicolumn{7}{|c|}{ Ano } \\
\hline & 1976 & 1977 & 1978 & 1979 & 1980 & 1981 & 1982 \\
\hline Taxa de câmbio nominal & 140 & 390,5 & 788,5 & 1316,5 & 1854,5 & 4525 & 15725 \\
\hline $\begin{array}{l}\text { Desvalorização nominal } \\
\text { anual da moeda }\end{array}$ & 438,8 & 178,9 & 101,9 & 67,0 & 40,9 & 144,0 & 247,5 \\
\hline $\begin{array}{l}\text { Índice da taxa de câmbio } \\
\text { real efetiva }\end{array}$ & 88,5 & 114,0 & 102,9 & 77,2 & 69,2 & 87,0 & 112,9 \\
\hline Tarifa máx. de importações & 210 & 100 & 100 & 83 & $\ldots$ & $\ldots$ & ... \\
\hline $\begin{array}{l}\text { Tarifa média de } \\
\text { importações }\end{array}$ & 55 & 41 & 33 & 24 & $\ldots$ & $\ldots$ & $\ldots$ \\
\hline Balança comercial & 1142,0 & 1846,0 & 2138,0 & 4225,0 & - 2598,0 & - 3193,0 & $-668,0$ \\
\hline $\begin{array}{l}\text { Exportações de bens e } \\
\text { serviços }\end{array}$ & 4610,0 & $-1827,0$ & $-2236,0$ & $-4424,0$ & 2666,0 & 3408,0 & 806,0 \\
\hline $\begin{array}{l}\text { Importações de bens e } \\
\text { serviços }\end{array}$ & 3468,0 & 1877,0 & 2520,0 & 403,0 & $-3191,0$ & $-757,0$ & 2667,0 \\
\hline Balança em conta corrente & 657,0 & 6588,0 & 7483,0 & 9177,0 & 9891,0 & 10854,0 & 9183,0 \\
\hline Conta capital & 261,0 & 4711,0 & 4962,0 & 8774,0 & 13081,0 & 11610,0 & 6516,0 \\
\hline $\begin{array}{l}\text { Saldo balanço de } \\
\text { pagamentos }\end{array}$ & 9,8 & 1127,0 & 1836,0 & $-535,0$ & $-4774,0$ & - 4712,0 & $-2354,0$ \\
\hline $\begin{array}{l}\text { Variação nas reservas } \\
\text { Internacionais }\end{array}$ & $-919,0$ & 719,0 & 302,0 & 4760,0 & 2176,0 & 1519,0 & 1686,0 \\
\hline
\end{tabular}

Fonte: Taxa de câmbio nominal e real, desvalorização da moeda: Ramos (1984): Anuário Estatístico da CEPAL, entre 1976 e 1983. Tarifas máximas e média de importações: Martínez de Hoz (1991). Contas do balanço de pagamentos: CEPAL (2009).

Notas: Índice de taxa de câmbio real efetiva com base em 1970(=100); Tarifas em porcentagem; Contas externas em milhões de US\$ corrente; Valores negativos da variação nas reservas internacionais significam aumentos.

Essa política implicou em um progressivo atraso cambial, ou seja, apesar das desvalorizações da taxa de câmbio em termos nominais, o câmbio real se valorizou. O índice da taxa de câmbio real diminuiu de 102,9 em 1977 para 69,2 em 1979, o que representa uma valorização real de quase 34\% (Tabela 6). Apesar da desaceleração a partir da tablita, a inflação nunca cedeu abaixo dos $100 \%$ e não houve convergência com a taxa de inflação internacional, o que contrasta com os resultados nessa matéria na experiência chilena.

A valorização cambial gerou consequências explosivas: o atraso cambial para desacelerar a inflação, ao estimular as importações e desestimular as exportações, resultou em uma crescente deterioração do saldo da balança 
comercial e de conta corrente, que por sua vez demandava crescentes taxas de juros para estimular a entrada de capitais estrangeiros para financiar esse déficit (Canitrot, 1980; Fausto e Devoto, 2004; Ramos, 1984). A valorização do câmbio real potencializou os efeitos da situação externa (Tabela 6). O endividamento externo foi notável no período, com aumento da dívida externa total, do setor público e do setor privado (Souza, 2007; Banco Central de la República Argentina, 1976-1983).

Tabela 7 - Indicadores de crescimento da Argentina (1976-1983)

\begin{tabular}{l|c|c|c|c|c|c|c}
\hline \multirow{2}{*}{ Indicador } & \multicolumn{7}{c}{ Ano } \\
\cline { 2 - 8 } & $\mathbf{1 9 7 6}$ & $\mathbf{1 9 7 7}$ & $\mathbf{1 9 7 8}$ & $\mathbf{1 9 7 9}$ & $\mathbf{1 9 8 0}$ & $\mathbf{1 9 8 1}$ & $\mathbf{1 9 8 2}$ \\
\hline $\begin{array}{l}\text { Produto Interno } \\
\text { Bruto (PIB) }\end{array}$ & 101956,5 & 108465,8 & 104971,9 & 112337,9 & 113970,4 & 107790,8 & 104385,7 \\
$\begin{array}{l}\text { Taxa de variação } \\
\text { do PIB }\end{array}$ & 0,0 & 6,4 & $-3,2$ & 7,0 & 1,5 & $-5,4$ & $-3,2$ \\
$\begin{array}{l}\text { PIB per capita } \\
\begin{array}{l}\text { Taxa de variação } \\
\text { do PIB }\end{array}\end{array}$ & 3853,5 & 4037,9 & 3849,9 & 4059,2 & 4056,8 & 3779,0 & 3604,1 \\
per capita & $-1,6$ & 4,8 & $-4,7$ & 5,4 & $-0,1$ & $-6,8$ & $-4,6$ \\
\hline
\end{tabular}

Fonte: CEPAL (2009).

Notas: Taxas de variação do PIB e do PIB per capita de um ano com relação ao ano anterior.

No total, a taxa de crescimento média do PIB e do PIB per capita no período de 1976 a 1983 foi, respectivamente, na ordem de 0,4 e -1,1\%, de tal modo que em 1982 o PIB era apenas levemente superior ao de 1976 e o PIB per capita era menor (Tabela 7). Esse crescimento é baixo mesmo se compararmos com outros períodos históricos de pouco crescimento, como por exemplo, entre 1970 e 1975, quando o PIB cresceu 2,9\% e o PIB per capita 1,2\% (CEPAL, 1984, p. 145-146). Na segunda fase, quando da nova política cambial, o crescimento econômico foi um pouco mais expressivo, mas ainda baixo (Ramos, 1984; Cano, 2000). O lento crescimento econômico não se expressou em elevadas taxas de desemprego na Argentina devido ao maior nível de investimentos públicos e, na verdade, a taxa de desemprego se situou abaixo de $5 \%$ em todo o período, com mínima no período da segunda fase, menor que $3 \%$ ao ano (Tabela 5 ).

No caso argentino, as reformas econômicas de longo prazo tiveram um raio de alcance mais limitado. De maneira geral os esforços de Martínez de Hoz ficaram concentrados na abertura comercial e, principalmente, na reforma financeira. 
Segundo Ferrer (2004), com a abertura comercial esperava-se a priori que os preços internos (especialmente os industriais) abaixassem pela elevação da concorrência, o que não ocorreu (Ferrer, 2004). Na reforma financeira, os resultados não foram satisfatórios, não houve convergência entre as taxas de juros interna e externa, e verificou-se que o sistema financeiro ocupou um lugar importante apenas no financiamento de curto prazo e o Estado mantinha sua importância nos investimentos de longo prazo (Rapoport, 2000).

Além disso, o processo de privatizações avançou pouco, na forma de "privatização periférica”. A privatização periférica significa que há, apesar da empresa se manter nas mãos do Estado, uma progressiva transferência de atividades para o setor privado por meio de contratos (Basualdo e Barrera, 2015). Canelo (2008) analisa que alguma das ações da privatização periférica se deram por exemplo na Yacimientos Petrolíferos Fiscales (YPF) (a empresa estatal de petróleo), na área ferroviária, de companhias aéreas, portos, correios, além disso, em privatizações de estabelecimentos provinciais e municipais, que não tinha muita importância econômica. Conforme já vimos, as limitações no caso do chileno foram menores.

\subsection{A terceira fase: as consequências da tablita para o setor externo}

$\mathrm{Na}$ terceira fase, os desequilíbrios do setor externo explodem na Argentina. A crise na balança de pagamentos e o comprometimento da solvência do sistema financeiro argentino são explicados por Ramos (1984) como tendo duas razões.

Primeiramente, a valorização cambial causou a perda de mercados internos e externos para muitas empresas, ocasionando déficits na conta corrente. Segundo, em função do risco cambial atrelado a esses déficits, optou-se pelo aumento da taxa de juros real em 1981, que já vinha permanecendo em níveis altos na segunda fase, causando maiores custos financeiros para as empresas. Assim, a reduzida credibilidade da política cambial do regime e os citados desequilíbrios macroeconômicos incentivaram a fuga de capitais, e a consequente pressão nas reservas internacionais obrigou o governo a incorrer em desvalorizações cambiais em uma magnitude que quintuplicou o câmbio durante o ano de 1981.

Em suma, das seções anteriores ressalta-se que o baixo crescimento, e a política de valorização cambial com efeitos negativos no balanço de pagamentos são características em comum das duas experiências. As diferenças mais 
significativas foram que a política de combate à inflação no Chile foi conjugada com drásticos cortes no investimento público e, além disso, as reformas estruturais foram mais extensas e profundas. Na Argentina, por outro lado, havia uma adoção mais pragmática, com a não diminuição do investimento público, e as reformas se deram de maneira limitada. Para entender essa divergência, sugerimos na próxima seção possíveis motivações.

\section{O radicalismo chileno e o pragmatismo argentino sob a ótica da formulação da política econômica}

Nesta seção, abordaremos questões que ajudam a explicar porque experiências de política econômica de uma mesma inspiração liberal tiveram caminhos na implementação e resultados diferentes. $\mathrm{O}$ argumento que pretendemos deixar claro na seção é o de que as divergências se devem ao maior grau de apoio de Pinochet, implicando em uma maior autonomia dos Chicago boys na perseguição de suas políticas econômicas liberais, enquanto na Argentina a relação dos militares com Martínez de Hoz era mais conflituosa, com muitos vetos, demandando opções de política econômica mais pragmáticas, em consonância com as possibilidades políticas. Ademais, havia um maior distanciamento em relação aos setores produtivos no caso chileno do que na Argentina, possibilitando maior imposição dos custos de estabilização e reformas. Nota-se que "afastamento" não significa neutralidade da política econômica.

\subsection{Os condicionantes para a política econômica no Chile: militares e setores produtivos}

Um dos primeiros pontos que podemos observar comparativamente é o grau de condicionamento dos militares. No Chile, os militares apoiaram mais as reformas neoliberais, ao passo que na Argentina os militares tinham inúmeros vetos à política econômica, como a não permissão à recessão e ao aumento do desemprego.

A importância do apoio de Pinochet para a realização das políticas econômicas e das reformas é reconhecida por inúmeros atores envolvidos no período. Em declarações realizadas ex-post, Sérgio de Castro, o líder e mais poderoso Ministro da Fazenda, reconhece no prólogo, escrito em 1992, quando da publicação do plano econômico El Ladrillo, a importância decisiva que, particularmente, teve o Presidente Augusto Pinochet: 
Muitos estranham e se perguntam como foi possível o Governo das Forças Armadas aplicar um programa libertário tão alheio aos conceitos de extrema centralização com que estas se caracterizam. [...] O modelo de uma economia social de mercado proposto para substituir o existente tinha coerência lógica e oferecia uma possibilidade de sair do subdesenvolvimento [...] não cabe dúvida que o mérito de haver mantido o rumo sem perder o objetivo verdadeiro e final corresponde inteiramente ao então Presidente da República (Castro, 1992, p. 12).

O maior apoio aos Chicago boys se manifestava também na aplicação radical sem hesitação da política anti-inflacionária, com redução dos gastos e investimentos públicos. Em discurso referente ao "Programa de Recuperación Económica" em 1975, Jorge Cauas, que não era estritamente um Chicago boy, pois se formou na Universidade de Columbia, argumenta que os funcionários públicos e as empresas estatais deveriam abdicar de seus próprios interesses porque "[...] carecem de toda importância frente a principal preocupação de todos os chilenos, que não é outra que a inflação" (Cauas, 1978a, p. 171, tradução nossa). Em outro discurso, o ministro reforça a importância das medidas mais duras: "[...] Tem-se pretendido desprestigiar a autoridade econômica acusando-a de insensibilidade social e de que implementamos uma política que favorece os setores mais ricos, em detrimento dos pobres do país [...]" (Cauas, 1978b, p. 202).

Relacionado com isso, a respeito do investimento público, no El Ladrillo os itens de "Vivienda y Urbanismo, Obras Públicas y Transporte e Minería" não foram divulgados com o restante do plano. Embora haja esse limite da fonte primária, há indicações ao longo do documento sobre a questão do investimento público. Particularmente sobre as obras públicas, remete-se especificamente à sua redução, assim como dos empregos absorvidos pela atividade, porque "[...] uma política de emprego direto [...] gera uma excessiva burocracia e mantêm um baixo nível de produtividade [...]" (Castro, 1992, p. 99, tradução nossa).

Conforme vimos as reformas estruturais mais profundas e extensas no Chile fazem parte do nosso argumento de que a experiência chilena foi radical em relação à argentina, na qual houve muitas resistências tanto na política anti-inflacionária quanto no encaminhamento das reformas estruturais. Isto não implica que no Chile não houve pontos específicos de pragmatismo, e tampouco significa que no Chile, não havia oposições a Pinochet ${ }^{2}$. Por exemplo, no caso das privatizações, apesar

\footnotetext{
${ }^{2}$ Registra-se que Pinochet e os Chicago boys também enfrentaram resistências no interior do governo, por exemplo, do General da Força Aérea Gustavo Leigh, membro da Junta Militar, até 1978, e de Rául Sáez,
} 
do extenso programa de privatizações chileno, como apresentamos na seção 2, os militares resistiram também à venda de empresas consideradas estratégicas, como a empresa do cobre. Mas essa restrição foi bem pequena quando comparada com o caso argentino, que se limitou apenas à "privatização periférica", justamente devido às resistências dos militares.

Pela análise do plano econômico o El ladrillo, fica explícito que os Chicago boys associavam modelo de Industrialização por Substituição de Importações (ISI) e a atuação de grupos políticos, que "politizavam" a estrutura econômica chilena (CASTRO, 1992). Uma radical mudança era proposta pelos economistas. Pablo Baraona - presidente do Banco Central em 1975 e Ministro da Economia ${ }^{3}$ entre 1976 e 1978 - em discurso proferido como motivo de celebração de 90 anos da Universidade Católica do Chile, explicita essa relação:

O ocorrido no Chile durante os anos 70 e 73 foi, sem nenhuma dúvida, o resultado necessário de um processo que foi incubado [...] Sem nenhuma dúvida, as forças que chegaram a consumar o sucedido nesses anos estavam presentes em nossa sociedade muito antes e aceleraram sua atividade $[. .$.$] compreendendo sob eles não só os partidos políticos,$ mas também [...] os grêmios e sindicatos, chegamos a conclusões muito claras (Baraona, 1978, p. 388, tradução nossa).

Essa visão manifestava um afastamento em relação aos setores produtivos e aos trabalhadores no processo decisório. Nosso argumento é que esse distanciamento foi importante para a implantação das políticas econômicas radicais, por exemplo, no combate à inflação, a despeito dos efeitos recessivos e perdas setoriais. Em entrevista a jornalistas e executivos do jornal La Tercera de la Hora em 14 de julho de 1974, o então Ministro da Economia - que se tornaria um dos Ministros da Fazenda mais poderosos do regime entre 1976 e 1981 - Sérgio de Castro realiza uma crítica elaborada na qual refuta contestações dos interesses industriais e aponta para a necessidade da rápida adequação produtiva às novas condições impostas pela política econômica.

Geralmente muita gente tende a definir a situação do país de acordo com sua própria situação [...] Quem está desempregado, afirma que

seu indicado para o cargo de Coordenação Econômica no início do governo. Os dois eram contrários ao tratamento de choque preconizado pelos Chicago boys, demandando, em seu lugar, uma estratégia gradualista de combate à inflação e no andamento das reformas. Para uma análise mais detalhada sobre os conflitos no interior do Estado, dos militares e dos economistas, tanto no Chile, quanto na Argentina, consultar Resende (2019).

${ }^{3}$ No Chile havia dois cargos mais direcionados à área econômica, o Ministério da Economia e o Ministério da Fazenda. O primeiro é subordinado ao último, que é o mais poderoso. Na Argentina, não há essa diferença, e o principal cargo Ministério da Economia foi ocupado por Martínez de Hoz durante o período analisado. 
todo mundo está desempregado. O industrial com problemas, afirma que todo o mundo industrial está com problemas [...] A indústria manufatureira tem que entrar em sintonia e compreender que aquelas que não são eficientes em longo prazo terão que mudar para setores mais eficientes (Léniz e Castro, p. 92-93, tradução nossa).

Em suma, constituímos nosso argumento que o regime militar chileno possibilitou um maior acordo e uma maior blindagem social na aplicação das medidas liberais, de forma que os Chicago boys alcançaram maior autonomia na elaboração e na implementação das políticas econômicas em relação aos setores produtivos, principalmente o industrial.

\subsection{Os condicionantes para a política econômica na Argentina: militares e setores produtivos}

Em relação aos condicionantes militares, no caso argentino é importante levar em conta que houve fortes resistências e tensões entre diferentes frações militares, o que teria gerado, segundo Marcos Novaro e Vicente Palermo (2007, p. 47), o "crônico dissenso e uma permanente falta de consistência das políticas adotadas". Tais conflitos na ditadura militar argentina eram de tal magnitude que há autores que enfatizam que "[...] as profundas divisões entre várias facções no governo militar foram talvez a única razão mais importante para a implosão econômica e política durante o período 1981-1982" (Viegel, 2010, p .82, tradução nossa). Além disso, essas subdivisões tinham uma reverberação importante em alianças e conflitos com e entre os economistas no interior do governo (Resende, 2019). Foge do nosso objetivo entrar tão profundamente nessas questões neste trabalho. Contudo, é preciso destacar que na Argentina, diferentemente da relação entre os Chicago boys e Pinochet no Chile, estas subdivisões e os conflitos decorrente delas foram um condicionante importante para o ecletismo e o pragmatismo das políticas praticadas por Martínez de Hoz.

Para Teichman (2001), Martínez de Hoz teve que trabalhar forte para alcançar poderes no processo decisório, havendo grande resistência dos militares e uma série de interesses econômicos, especialmente dos nacionalistas que se opuseram em relação, por exemplo, ao processo de privatização. A autora sumariza que o processo de privatização não avançou, mas apenas no que foi chamado de "privatização periférica", e a abertura comercial sofreu resistências dos militares preocupados em proteger as indústrias militares. 
Em função do menor apoio dos militares, e as dificuldades de consenso em seu interior, é possível também observar nos discursos de Martínez de Hoz esse pragmatismo e discursos destoantes em vários assuntos. Em termos de emprego e inversão pública, Martínez de Hoz externaliza como articulador, dois sinais, para agradar determinados setores da sociedade, como os militares e os críticos. Esta certa "hesitação" se reflete primeiramente na inversão pública, ora declarando que os imperativos legais e os herdados em relação às obras não concluídas da gestão do governo anterior não permitiram a redução (Martínez de Hoz, 2016b), ora anunciando projetos de longo prazo de inversão pública (Martínez de Hoz, 2016c). De igual maneira, ao mesmo tempo em que discursa defendendo-se das críticas quanto à diminuição do funcionalismo (Martínez de Hoz, 2016b), afirma que o processo não seguiu pela situação de recessão do país, e ainda pontua como positivo as baixas taxas de desemprego vigentes no país, e pontua que no Chile, por se tratar de um país com estrutura produtiva simples, foi possível abaixar as tarifas externas mais rapidamente, e algo que na Argentina estaria ocorrendo de maneira mais gradual (Martínez de Hoz, 2016c).

Apesar de partilhar de um mesmo diagnóstico que no Chile, no discurso no qual anunciou o Programa de recuperación, saneamento y expansión, na Argentina, Martínez de Hoz assinalou que a política de redução do déficit público seria realizada de maneira gradual:

É como se um carro estivesse andando a mil quilômetros por hora e tentássemos freá-lo rapidamente. Fisicamente é impossível [...] ainda se fosse possível, se conseguisse, os passageiros desse carro, que representam a população argentina, sofreriam um golpe de tal natureza contra os para-brisas ou contra os bancos do carro, que provavelmente morreriam ou seriam seriamente lesionados [...] (Martínez de Hoz, 1981, p. 354, tradução nossa).

A orientação mais gradual se estendia a todas as áreas do governo, para a construção de um sistema de mercado livre: "[...] façam essa transição destes dois sistemas tão opostos, de uma maneira mais suave possível, sem brusquidão, sem saltos grandes” (Martínez de Hoz, 2016e, p. 18, tradução nossa).

Embora Martínez de Hoz também pontuasse, como no caso chileno, a necessidade de uma mudança da estratégia de desenvolvimento econômico para os setores primários, principalmente a agricultura, observamos em seus discursos um peso maior em relação à indústria voltada para o mercado interno. Como exemplo disso, em um discurso cita a execução de um dos maiores projetos industriais dos 
últimos anos, a Celulosa Argentina no valor de 500 milhões de dólares, e do Alto Paraná de 350 milhões de dólares. Esses projetos visavam atender às necessidades nacionais de celulose e papel (Martínez de Hoz, 2016c, p. 80).

Mesmo com a busca pela alteração do modelo de desenvolvimento, esse maior peso para a indústria é relatado na literatura (Ramos, 1984; Belini, 2017). Ao contrário dos discursos dos ministros chilenos, Martínez de Hoz no início do governo sinalizou maior abertura ao diálogo e à conciliação com os empresários, pelo menos até 1978.

Em mensagem no fim de dezembro de 1976, Martínez de Hoz externaliza que as decisões estariam sendo tomadas em conjunto com outros ministérios e atento aos efeitos sobre os setores produtivos

[...] pela primeira vez na história do país, temos recorrido a um procedimento - cremos - que será sumamente útil. Consideramos que esta não deve ser apenas da responsabilidade da Secretária de Finanças ou do Ministro da Economia, uma vez que, com este procedimento, por vezes aplicado através de cortes um pouco ditatoriais no orçamento, dá lugar a reclamações de todos os sectores [...] (Martínez de Hoz, 2016d, p. 113, tradução nossa).

Outra dimensão disso pode ser representada pelo apreço pessoal do Ministro pelos membros da agricultura. Em discurso no ato de encerramento do XII Congresso Cooperativo Agrário de 8 de setembro de 1978, expressou publicamente que o "[...] governo necessita ter interlocutores válidos no setor privado para poder dialogar com eles, para poder receber suas ideias, suas aspirações, suas expressões, suas críticas, suas observações [...]" (Martínez de Hoz, 2016a, p. 367, tradução nossa).

A partir de 1978 os discursos destoam, pois o ministro possui um discurso mais duro em relação ao modelo de desenvolvimento econômico pensado para a economia argentina, e o papel da indústria neste, bem como responde com atritos mais abertos com os setores produtivos. As declarações de Martínez de Hoz sinalizam uma diferença de atitude em termos de dosagem do gradualismo e maior afastamento em relação aos setores produtivos, defendendo a política de valorização cambial e a abertura comercial e um maior ajustamento do setor industrial a essa política, ao mesmo tempo que os níveis de investimento público continuavam elevados (Martínez de Hoz, 2016f). É justamente nessas posições que buscamos recapitular, ora com medidas e discursos mais pragmáticos, ora com 
alguns pontos de radicalidade, que pontuamos a diferença em relação ao caso chileno.

A tablita, mesmo com potenciais efeitos sob os setores exportadores, era uma estratégia com viabilidade política porque prometia à redução da inflação sem recessão, justamente o que era perseguido desde o início do governo pela equipe econômica de Martínez de Hoz, o que não implicaria ademais desgaste com a Junta Militar (Heredia, 2004). Do ponto de vista da comparação da formulação da política econômica, mesmo com a realidade impondo questionamentos em relação às explicações sobre o diagnóstico monetarista em ambos os casos, no Chile o instrumento de valorização cambial foi associado com a continuação do tratamento de choque de diminuição dos gastos e investimentos públicos.

Em resumo, à luz da análise dos discursos indicados anteriormente sugerimos que o regime militar argentino concedia a Martínez de Hoz menor autonomia e que, por isso, havia uma blindagem social com menor intensidade em relação aos setores produtivos, fundamentalmente o setor industrial, resultando em uma política econômica mais pragmática e eclética.

\section{Considerações finais}

Como pudemos observar, na Argentina não se avançou como no Chile na política de estabilização anti-inflacionária, e tampouco nas reformas estruturais, que foram de maneira geral limitadas. Na Argentina, em geral, prevaleceu uma política mais pragmática. A política econômica não conseguiu solucionar o problema da inflação, e a economia teve um comportamento variável em termos de crescimento entre os anos, mas que no agregado também apresentou desempenho tímido. A questão do investimento público é um aspecto fundamental que diferencia as experiências, por se tratar de uma evidência do grau de blindagem social dos regimes.

Aliás, este é o aspecto para o qual buscamos chamar atenção no artigo. Por trás dessa descrição e comparação geral, há questões relacionadas com a formulação da política econômica, que não devem ser tomadas como dimensões passivas ou desassociadas. Dentre várias dimensões que podem ser levadas em conta no sentido da formulação, destacamos neste trabalho a importância dos condicionamentos impostos pelos militares à política econômica, isto é, a relação entre os militares e os economistas que estavam à frente da gestão 
macroeconômica, e o grau de blindagem social proporcionada por cada regime em relação aos setores produtivos.

Neste sentido, argumentamos que o radicalismo da política econômica chilena e o pragmatismo, ecletismo e maior dificuldade da política econômica de Martínez de Hoz se relacionam com o maior apoio de Pinochet aos Chicago boys no prosseguimento das políticas econômicas radicais, enquanto na Argentina as divisões internas das Forças Armadas condicionavam de forma importante o prosseguimento da política econômica liberal. Isso se manifestava em um maior grau de blindagem social em relação aos setores produtivos no caso chileno do que no argentino, especialmente no setor industrial. Em outras palavras, os Chicago boys podiam suportar maiores custos de uma política recessiva e das reformas estruturais do que Martínez de Hoz.

\section{Agradecimentos}

O presente trabalho foi realizado com apoio da Coordenação de Aperfeiçoamento de Pessoal de Nível Superior (CAPES) - Código de Financiamento 001. Registro ainda a minha gratidão aos professores Roberto Pereira Silva, pelas sugestões e, em especial, pelo profícuo período de orientação da Dissertação, e Carlos Eduardo Suprinyak pelos comentários em uma versão preliminar. Estendo meus agradecimentos aos pareceristas anônimos que avaliaram o artigo, cujas críticas e sugestões foram de suma importância para a melhoria do artigo. 


\section{Referências}

ANGELL, A. Chile: 1958-c. 1990. In: BETHELL, Leslie (org.). Historia de América Latina: el cono sur desde 1930. Barcelona: Crítica, v. 15, cap. 6, p. 255213, 2002.

ARENAS DE MESA, Alberto. Historia de la reforma previsional chilena: una experiencia exitosa de política pública en democracia. Santiago: Oficina Internacional del Trabajo, 2010.

BANCO CENTRAL DE CHILE. Indicadores económicos y sociales de Chile: 1960-2000. Santiago, Departamento Publicaciones de la Gerencia de Investigación Económica, 2001.

BANCO CENTRAL DE LA REPÚBLICA ARGENTINA. Memoria anual. Buenos Aires: Banco Central de la República Argentina, 1976 e 1983.

BARAONA, P. A. Economía y Nueva Institucionalidad: Pablo Baraona Urzúa Ministro de Economía. In: DIPRES. Somos realmente independientes gracias al esfuerzo de todos los chilenos. Santiago: Ministerio de Hacienda, 1978.

BASUALDO, E. M.; BARRERA, M. A. Las privatizaciones periféricas en la ditadura cívico-militar: el caso de YPF en la producción de petróleo. Desarrollo Económico, p. 279-304, 2015.

BELINI, C. Historia de la industria en la Argentina: de la Independencia a la crisis de 2001. Sudamericana, Buenos Aires, n. 30, 2017.

BIELSCHOWSKY, R. Introdução geral. In: BIELSCHOWSKY, R. Pensamento econômico brasileiro: o ciclo ideológico do desenvolvimentismo. 4. ed. Rio de Janeiro: Contraponto, p.11-29, 2000.

CANELO, P. El proceso en su laberinto: la interna militar de Videla a Bignone. Prometeo Libros Editorial, 2008.

CANITROT, A. La disciplina como objetivo de la política económica: un ensayo sobre el programa económico del gobierno argentino desde 1976. Desarrollo Económico, v. 19, n. 76, p. 453-475, 1980.

CANO, W. Soberania e política econômica: o retrocesso pós 1979. In: CANO, W. Soberania e política econômica na América Latina. São Paulo: Editora Unesp, p. 11-80, 2000.

CASTRO, S. de. El ladrillo: bases de la política económica del Gobierno Militar Chileno. Santiago de Chile: Centro de Estudios Públicos, 1992.

CASTRO, S. de. Exposición sobre el Estado de la Hacienda Pública. Santiago: Ministerio de Hacienda, 1981. 
CAUAS, J. El Programa de Recuperación Económica del Gobierno: 24 abr. 1975. In: DIPRES. Somos realmente independientes gracias al esfuerzo de todos los chilenos. Santiago: Ministerio de Hacienda, 1978a.

CAUAS, J. Exposición sobre el Estado de la Hacienda Pública: out. 1975. In: DIPRES. Somos realmente independientes gracias al esfuerzo de todos los chilenos. Santiago: Ministerio de Hacienda, 1978b.

CEPAL. América Latina y el Caribe: series históricas de estadísticas económicas 1950-2008. Santiago de Chile: CEPAL, 2009.

CEPAL. Anuário Estatístico da América Latina e do Caribe. Santiago de Chile: CEPAL, entre 1975 e 1983.

CÓRTAZAR, R.; MARSHALL, J. Indice de precios al consumidor en Chile: 1970-1980. Santiago: Colección de Estudios CIEPLAN 4, p. 159-201, 1980.

FAUSTO, B.; DEVOTO, F. J. Ditadura, democratização e o tempo mais recente: 1968-2002. In: FAUSTO, B.; DEVOTO, F. J. Brasil e Argentina: um ensaio de história comparada: 1850-2002. São Paulo, Editora 34, p. 395-502, 2004.

FERRER, A. La economia argentina: desde sus origines hasta principios del siglo XXI. 3. ed. Buenos Aires: Fondo de Cultura Económica, 2004.

FFRENCH-DAVIS, R. Entre el neoliberalismo y el crecimiento con equidad: tres décadas de política económica en Chile. 3 ed. aum. actual. Santiago: LOM Ediciones, 2003.

FFRENCH-DAVIS, R.; MUÑOZ, O.; PALMA, J. G. As economias latinoamericanas:1950-1990. In: BETHELL, L. (org.). A América Latina após 1930. São Paulo: EDUSP, v. 6, p. 129-228, 2005.

FUENTES, C.; VALDEAVELLANO, R. Chicago boys. Santiago: La Ventana Cine, 2015.

HEREDIA, M. El proceso como bisagra: emergencia y consolidación del liberalismo tecnocrático. In: ANSALDI, Waldo.; PUCCIARELLI, Alfredo. Empresarios, tecnócratas y militares: la trama corporativa de la última dictadura. Buenos Aires: Siglo XXI, v. 197, 2004.

JADRESIC, E. Evolución del empleo y desempleo en Chile: 1970-85. Colección Estudios CIEPLAN, n. 20, p. 147-193, 1986.

JADRESIC, E. Salarios en el largo plazo: Chile 1960-1989. Colección estudios CIEPLAN, n. 29, p. 9-34, 1990. 
LÉNIZ, F.; CASTRO, S. de. Entrevista al Ministro da Economia Fernando Léniz: la tercera, 14 jul. 1974. In: DIPRES. Somos realmente independientes gracias al esfuerzo de todos los chilenos. Santiago: Ministerio de Hacienda, 1978.

MARSHALL, J.; SCHMIDT-HEBBEL, K. Chile: Fiscal adjustament and sucessful performance. In: EASTERLY, W.; SCHMIDT-HEBBEL, K. Public Fiscal Deficits and Macroeconomic Performance. Oxford: Oxford University Press, p. 167-225, 1991.

MARTINEZ DE HOZ, J. A. Discurso en al acto de clausura del VII Congreso Cooperativo Agrario: 8 set. 1978. In: MINISTERIO DE HACIENDA Y FINANZAS PÚBLICAS. Memoria Ministerio de Economía 29 de marzo de 1976/29 de marzo de 1981. Ciudad Autónoma de Buenos Aires: Centro de Documentación e Información, p. 356-371, 2016 a.

MARTINEZ DE HOZ, J. A. Entrevista radical efectuada como referencia a la pauta cambiaria: 16 jun. 1980. In: ARGENTINA. Ministerio de Hacienda y Finanzas Públicas. Memoria Ministerio de Economía 29 de marzo de 1976/29 de marzo de 1981. Ciudad Autónoma de Buenos Aires: Centro de Documentación e Información, p. 699-700, 2016 b.

MARTINEZ DE HOZ, J. A. Mensaje a todo país por radiotelefonía y televisión, sobre le ejecución del programa económico en 1976 y las perspectivas para 1977: 23 dez. 1976. In: ARGENTINA. Ministerio de Hacienda y Finanzas Públicas. Memoria Ministerio de Economía 29 de marzo de 1976/29 de marzo de 1981. Ciudad Autónoma de Buenos Aires: Centro de Documentación e Información, p. 109-114, 2016d.

MARTINEZ DE HOZ, J. A. Mensaje por la cadena nacional de radiotelefonía y televisión a todo el país desde la provincia de Córdoba, sobre lo realizado en 6 meses de gobierno: 29 set. 1976. In: ARGENTINA. Ministerio de Hacienda y Finanzas Públicas. Memoria Ministerio de Economía 29 de marzo de 1976/29 de marzo de 1981. Ciudad Autónoma de Buenos Aires: Centro de Documentación e Información, p. 75-84, 2016c.

MARTINEZ DE HOZ, J. A. Política de Precios: 12 abr. 1976. In: ARGENTINA. Ministerio de Hacienda y Finanzas Públicas. Memoria Ministerio de Economía 29 de marzo de 1976/29 de marzo de 1981. Ciudad Autónoma de Buenos Aires: Centro de Documentación e Información, 2016e. p. 16-18.

MARTINEZ DE HOZ, J. A. Programa de recuperación, saneamiento y expansión de la economía argentina. In: PALACIO DEHEZA, C. El plan Martínez de Hoz y la economía argentina. Buenos Aires: Corregidor, p. 346-384, 1981.

MARTINEZ DE HOZ, J. A. Quince anõs después. Buenos Aires: Eméce Editores, 1991. Disponível em: <http://www.martinezdehoz.com/words/15_a\%C3\%B 1os_despues.pdf >. Acesso em: 15 out. 2018. 
MARTINEZ DE HOZ, J. A. Reportaje efectuado en el programa "Análisis a fondo", canal 9, sobre política cambiaria y otros temas de actualidad: 20 mar. 1979. In: ARGENTINA. Ministerio de Hacienda y Finanzas Públicas. Memoria Ministerio de Economía 29 de marzo de 1976/29 de marzo de 1981. Ciudad Autónoma de Buenos Aires: Centro de Documentación e Información, p. 475-478, $2016 f$.

NOVARO, M.; PALERMO, V. A ditadura militar argentina: 1976-1983: do golpe de estado à restauração democrática. São Paulo: Edusp, 2007.

RAMOS, J. Estabilización y liberalización económica en el Cono Sur. Santiago: CEPAL, 1984.

RAMOS, J. Inflación persistente, inflación reprimada e hiperestanflación: lecciones de inflación y estabilización en Chile. Cuadernos de Economía, n. 43, p. 65-108, 1977.

RAPOPORT, M. Historia económica, política y social de la Argentina. Buenos Aires: Editorial Macchi, 2000.

RESENDE, M. T. Liberalismo e tecnocracia: um estudo comparativo das políticas econômicas nos regimes autoritários do Chile (1973-1982) e da Argentina (19761982). 2019. 242f. Dissertação (Mestrado em Economia) - Instituto de Ciências Sociais Aplicadas (ICSA). Universidade Federal de Alfenas, Varginha, 2019.

RODRÍGUEZ, C. A. Fiscal disequilibria leading to hyperinflation. In: EASTERLY, W.; SCHMIDT-HEBBEL, K. Public Fiscal Deficits and Macroeconomic Performance. Oxford: Oxford University Press, p. 101-165, 1994.

SOUZA, L. E. S. de. A Arquitetura de uma crise: História e política econômica na Argentina, 1989-2002. 2007. 336f. Tese (Doutorado em História Econômica) Faculdade de Filosofia, Letras e Ciências Humanas. Universidade de São Paulo, 2007.

TEICHMAN, J. A. The politics of freeing markets in Latin America: Chile, Argentina, and Mexico. Univ of North Carolina Press, 2001.

TORRE, J. C; RIZ, L. Argentina 1946-c. 1990. In: BETHELL, Leslie (org.). Historia de América Latina: el cono sur desde 1930. Barcelona: Crítica, v. 15, p. 60-155, 2002.

VALDÉS, J. G. Pinochet's Economists: the Chicago School of economics in Chile. Cambridge: Cambridge University Press, 1995.

VEIGEL, K. F. Dictatorship, democracy, and globalization: Argentina and the cost of paralysis: 1973-2001. Pennsylvania: Pennsylvania State University Press, 2010 . 
YÁÑEZ, J. Nota técnica: Índice de Precios al Consumidor. Santiago: Universidad de Chile, Departamento de Economia, v. 11, p. 117-11, 1984. 